\title{
The Analysis of Industrial Isomorphism in the Industrial Park of Yunnan Province
}

\author{
Zetao Zhang \\ International Business School \\ Yunnan University of Finance and Economics \\ Kunming, China
}

\author{
Shushu Feng* \\ International Business School \\ Yunnan University of Finance and Economics \\ Kunming, China \\ *Corresponding Author
}

\begin{abstract}
With the rapid economic development, Yunnan Province faced the problem of unbalanced market competition and coordination among the cities and industrial parks. Under the situation of unreasonable division of labor in industrial structure and the existence of industrial isomorphism, how to strengthen the competitiveness of the industrial parks in Yunnan has become a problem. This paper picked 10 typical industrial parks in Yunnan, and measured 3 major industrial structure and $\mathbf{3}$ major industrial categories in these parks. It is found that the major industries in these parks are overlapped. Suggestions are provided at the end to this problem.
\end{abstract}

Keywords-industry isomorphism; industrial park; similar coefficient index

\section{INTRODUCTION}

Industrial Park is a specific zone that is planned for the purpose of industrial development. Through intensification and agglomeration, various production factors are gathered in the parks and competitive advantage of clusters has been given full play. Industrial park model plays a critical role in modern industrial production and in the market competition. China started the industrial park model back in 1978. Up until September 2015, 219 state- level Economic and Technological Development Zone and 114 state-level High and New Technology Development Zone have been established. ${ }^{1}$ In 2016, there are 219 state-level Economic Development Zone, which realized RMB 820 million gross regional products and contributed $11 \%$ of China's GDP. It is recognized that industrial is critical in promoting China's industrial layout optimization, changing the economic growth mode, expanding the regional production and promoting the transformation of government functions.

Yunnan is located in the southwestern part of China, which is considered an important bridgehead facing Southeast and South Asia, and is also an important strategic area along the B\&R Initiative. ${ }^{2}$ Until 2016, Yunnan has established 132 industrial parks, which include 7 State-level parks, 63 Province-level parks and 62 City-level parks, which have a total revue of RMB 1,248 billion. There are 22 industrial parks whose annual revenue have exceeded RMB 10 billion and

Data Source: www.ocn.com.cn

Data Source: http://www.yn.gov.cn/yn_zwlanmu/ comprised $73 \%$ of the revenue among the industrial parks in Yunnan. The construction of Industrial Parks has greatly promoted the transformation of Yunnan's industrial development model, and has become the model of industrial restructuring and new industrialization construction as well as the engine of economic growth in Yunnan Province.

However, due to the factors of late start, weak foundation and insufficient regional development, the further construction and development of those industrial parks have encountered lots of problems, particularly, industry isomorphism. How to solve these problems becomes a hot topic for the researchers.

\section{LITERATURE REVIEW}

The study of industrial park started with the conception of industrial cluster. Weber (1929) [1] believed that industrial cluster is the geographical concentration of small enterprises, supporting enterprises within a certain scope. Granovetter (1985) [2] put forward that industrial park is a "loosely coupled system" in which these systems actively coordinate organizations in order to achieve synergies and ultimately better production and international competition. When technology revolution changed the production mode from mass and standardized production to small batch and customization, Industrial Park is such a carrier, which bears the agglomeration flexible modes of production (Scott, 1992)[3]. The concept of New Industrial Zone was introduced (Wang, 2001) [4] and a series of researches were conducted in regarding to the significance of development industrial parks (Chen, 2003) [5]).

When discussing the layout of industrial park, Wu (2014)[6] pointed out that the reason for the imbalance between the East and the West of China's industrial spatial distribution lies in the deviation of the optimal agglomeration of the market and society, and the absence of the transfer function between the eastern region and the domestic value chain. Li (2015) [7] analyzed correlation coefficient between the urbanization and the three industries level of Qingdao from 1992 to 2012 a, and draw the conclusion that the industrial layout of Qingdao is constantly optimized. When it comes to Yunnan Province, Jia (2014)[8] raised the problem of low energy utilization and low value added products contributed to the problem of Yunnan's industry structure and concluded that the role of industry policies should guide the cultivate new industries, and accelerate the upgrading of industries. Liu (2016) [9] 
summarized the status quo of the industrial parks in Yunnan and gave guidance on the financing system building of the parks. Because the functions, structures, functions and meanings of industrial parks are becoming diversified, specialized and concrete, Industrial Parks are not only geographic industrial agglomeration of enterprises, but also a complex of complementary functions, resource sharing and collaborative competition between enterprises and enterprises. It is not only the carrier of harmonious coexistence between enterprises and natural environment, but also an important contributor to regional economic GDP.

\section{THE STATUS QUO OF YUNNAN'S INDUSTRIAL PARK}

Yunnan province is in the middle stage of industrialization as a whole. At a certain stage of economic development, it will inevitably go through a process of convergence of industrial structure, then divergence, and finally convergence. Industrial isomorphism refers to the tendency of similarity of industrial structure layout and development among different industrial parks or within the industrial parks in the process of industrial structure development. This is an inevitable process and as long as it is controlled within a reasonable range, it will benefit the sustainable and healthy development of the industrial parks.

\section{A. Introduction of Yunnan Province's Industrial Park}

Based on 2013 Yunnan Statistics Yearbook, The total output value of all the parks in Yunnan Province is RMB 882.3 billion, while the total GDP of the whole province is RMB 1172.09 billion. The contribution rate of the output value of the parks to the industrial added value of the whole province is as high as $75 \%$. Since 2011 , for three consecutive years, the proportion of Industrial Park added value in the total GDP of Yunnan Province has been increasing continuously, accounting for $61 \%, 70 \%$ and $75 \%$ respectively. This shows that the construction of industrial park plays a vital role in the economic development of Yunnan Province.

TABLE I. THE INDUSTRIAL PARK’s CONTRIBUTION TO GDP IN 2012

\begin{tabular}{|l|l|l|l|}
\hline & $\begin{array}{c}\text { Regional } \\
\text { GDP(in } \\
\text { billion RMB) }\end{array}$ & $\begin{array}{c}\text { Industrial } \\
\text { Park Output } \\
\text { (in billion } \\
\text { RMB) }\end{array}$ & $\begin{array}{c}\text { GDP } \\
\text { Contribution } \\
(\%)\end{array}$ \\
\hline Kunming & 301.11 & 280.78 & 93 \\
\hline Qujing & 140.01 & 94.03 & 67 \\
\hline Yuxi & 112.45 & 100.01 & 89 \\
\hline Baoshan & 38.99 & 11.88 & 30 \\
\hline Zhaotong & 55.56 & 16.54 & 30 \\
\hline Lijiang & 21.22 & 5.42 & 26 \\
\hline Puer & 36.68 & 8.75 & 24 \\
\hline Lincang & 35.30 & 6.35 & 18 \\
\hline Dehong & 20.10 & 6.25 & 31 \\
\hline Nujiang & 7.49 & 2.03 & 27 \\
\hline Qiqing & 11.36 & 2.11 & 19 \\
\hline Dali & 67.20 & 53.48 & 80 \\
\hline Chuxiong & 57.00 & 37.64 & 66 \\
\hline Honghe & 90.54 & 61.03 & 67 \\
\hline Wenshan & 478.02 & 185.65 & 39 \\
\hline Xishuangbanna & 232.64 & 9.01 & 4 \\
\hline Province Level & 1030.95 & 718.25 & 70 \\
\hline & & & \\
\hline
\end{tabular}

a. Data Source: Yunnan Satistical Yarbook 2016
It is obvious that the construction and development of the park not only plays a vital role in the GDP of Yunnan Province, but also makes a great contribution to the economic development of the prefecture. In 2012, the contribution rate of Kunming Industrial Park accounted for $93 \%$ of the Kunming's GDP, and Yuxi Industrial Park output value accounted for more than $89 \%$ of the city's GDP.

On November 9, 2016, the Government of Yunnan Province issued the "Industrial Park Industrial Distribution Planning of Yunnan Province (2016-2025)", hereinafter referred to as the "Planning", and defined the "13th Five-Year Plan" in the eight key industries, which are biomedicine, information industry, metallurgy, tobacco, chemical industry, manufacturing, building materials and new materials. The Planning divides the whole province into three major industrial regions, and has different orientations for the industrial functions of the three regions. One is the "innovation leading area", including Kunming, Qujing, Yuxi and Chuxiong; the other is the "industrial speed-up and efficiency-increasing area", including Dali, Baoshan, Honghe, Wenshan and Zhaotong; and the third is the "border opening and opening up" Green Development Zone, which includes Dehong, Lincang, Pu'er, Xishuangbanna, Lijiang, Diqing and Nujiang.

\section{B. Similarity Coefficient Index of Industrial Stucture}

Similarity Coefficient Index was introduced by UNIDO in 1980 s and it is used to calculate the structure similarity for different regions.

$$
S_{i j}=\sum_{k=1}^{n} x_{i k} x_{j k} / \sqrt{\sum_{k=1}^{n} x_{i k}^{2} \sum_{k=1}^{n} x_{j k}^{2}}
$$

$S_{\mathrm{ij}}$ is the similarity coefficient of region $\mathrm{i}$ and $\mathrm{j} . \mathrm{X}_{\mathrm{ik}}$ is the total industrial output value of $\mathrm{k}$ industry accounts for the proportion of the total $n$ industrial output value of the $i$ area. $X_{\mathrm{jk}}$ is the total industrial output value of $\mathrm{k}$ industry accounts for the proportion of the total $n$ industrial output value of the $\mathrm{j}$ area.

When $S_{i j}=0$, which means region $\mathrm{i}$ and region $\mathrm{j}$ has totally different industrial structure; When $S_{i j}=1$, which means region $\mathrm{i}$ and region $\mathrm{j}$ has the same industrial structure; When $0<S_{i j}<1$, which represents that region $\mathrm{i}$ and region $\mathrm{j}$ has similar industrial structure and the degree of similarity is determined by the value of $S_{i j}$. The more close to 1 , the more similar is the two regions industrial structure. The set of Similarity Coefficient Index are calculated for the 16 cities in Yunnan in 2017.

\section{Similarity Coefficient Index of Yunnan's Industrial Park}

Based on the Planning and layout of these parks, we picked 10 industrial parks in Yunnan to see their similarity coefficient index. We measure the industrial structure of primary industry, second industry and third industry, and get the similarity coefficient of the two regions in order to judge the degree of overlapping. 
TABLE II. The Similarity INDEX OF THE 10 INDUSTRIAL PARK IN YUNNAN IN 2017

\begin{tabular}{|c|c|c|c|c|c|c|c|c|c|c|}
\hline Region & Chogming & Lufeng & Shidian & Jianshui & Zhanyi & Chuxiong & Mengi & Gejiu & Yuxi & Jinghong \\
\hline Chongming & 1.00 & 0.93 & 0.99 & 0.95 & 0.91 & 0.99 & 0.97 & 0.98 & 0.99 & 0.93 \\
\hline Lufeng & & 1.00 & 0.91 & 0.96 & 0.98 & 0.87 & 0.97 & 0.90 & 0.89 & 0.92 \\
\hline Shidian & & & 1.00 & 0.94 & 0.89 & 0.99 & 0.97 & 0.97 & 0.99 & 0.91 \\
\hline Jianshui & & & & 1.00 & 0.98 & 0.91 & 0.99 & 0.97 & 0.93 & 0.99 \\
\hline Zhanyi & & & & & 1.00 & 0.85 & 0.97 & 0.92 & 0.88 & 0.97 \\
\hline Chuxiong & & & & & & 1.00 & 0.94 & 0.97 & 0.99 & 0.89 \\
\hline Mengzi & & & & & & & 1.00 & 0.97 & 0.96 & 0.97 \\
\hline Gejiu & & & & & & & & 1.00 & 0.97 & 0.97 \\
\hline Yuxi & & & & & & & & & 1.00 & 0.91 \\
\hline Jinghong & & & & & & & & & & 1.00 \\
\hline
\end{tabular}

It can be concluded from "Table II" that of the 45 calculated results, 40 have structural similarity of more than 0.9 , accounting for $89 \%$. Among them, the overlap degree of industrial structure of Chongming and Shidian, Chonmging and Chuxiong, Chongming and Yuxi, Shidian and Yuxi, Jianshui and Mengzi is over 0.99. Even the lowest number is 0.853 , which are between Zhanyi and Chuxiong. The industrial parks in Yunnan Province have a high degree of overlap in industrial structure.

\section{REASONS FOR THE INDUSTRIAL ISOMORPHISM}

First of all, the county governance mode and its incentive mechanism contributes to the industrial isomorphism Before the founding of the People's Republic of China, China's economic foundation was very weak, and it was unable to build a complete economic system and industrial system, mainly agricultural economy. When the reform and open-up policy established, the target management system was carried out, which indirectly lead the pursuit of GDP growth as the only aim for the government. GDP growth has become an important indicator of the political promotion of government managers. The fierce competition among local governments makes the leaders have to use administrative power to intervene in the economy. They concentrate on developing a number of industries that are already in the mature markets, have large short-term returns, while have small development potential and resource-consuming in order to obtain more fiscal revenue.

In addition, the inertia of planned economy is also the cause of the industrial overlap. Before the reform and opening-up, China implemented a planned economy in which social resources were allocated at the national level. Social resources were rigidly and centralized in the process of allocation, regardless of the geographical advantages of resources and the enthusiasm and creativity of regional economy, thus the market deviated from the supply and demand relationship of the market. Without the market competition, economic activities are slow, the efficiency of resource allocation is restrained, and regional industrial convergence and duplicate construction is difficult to get timely feedback. The phenomenon of industrial structure convergence and county economic overlapping, were left over by long-term planned economy, still exists today.

Thirdly, it is the adverse selection of dual competition under planned economy and market economy system. When planned economy is transforming into a market economy, government led economy is weakening, but there is still political interference. The imperfection of the economic system, the blindness of the market, the dominance of administrative power and the immaturity of the market economy also lead to the convergence of the industrial structure and the overlap of the county economy. At the same time, the uneven distribution of social resources, the lag enterprise reform and the imperfection of property rights market caused by the slow reform of national economic system have also directly hindered the transfer and concentration of resources to industries with high income, high output, low pollution and low cost.

Last but not least, the disorder competitive advantage and post development catch-up strategy. The development of market economy makes enterprises become the main body of the market. In the process of development, the choice of location and the advantages of their own industries are the keys to exert the agglomeration effect of enterprises. In the case of the combination of natural resources endowment and comparative advantage, the convergence of industrial structure emerged. As a new enterprise or the government which lags behind, whether its aim is to pursue more benefits or more revenue, it will put resources into the industry with mature technology, high income, low cost and short investment return period. Therefore, the convergence of industrial structure is inevitable.

\section{CONCLUSION}

The development of industrial parks in Yunnan Province started relatively late, compared with the developed eastern coastal areas. It has the characteristics of low level of construction, low starting point, inadequate investment, and is restricted by regional economic and geographical conditions. But at the same time, the construction of industrial parks is also an important supporting role for the local economy and even the whole province's economy. The key to healthy, sustainable, stable and comprehensive construction of industrial parks lies in rational layout, overall planning, and striving to avoid or reduce industrial overlap in the process of park construction. Although this paper uses the similarity coefficient index to measure the industrial overlap of Yunnan industrial parks, the industrial structure of the parks is a complex system, which cannot be completely replaced by the GDP of the localities. Based on the analysis of the present situation of industrial park construction and development in Yunnan Province and the causes of industrial overlap in industrial park, the following strategies are put forward for the construction and development of industrial park. 
1) Strengthening industrial planning process to realizie economic zone development mode: The economic development of the city cannot be fighting alone especially for the county and industrial parks within a small area. It is important to adjust the layout of industrial planning, optimize the industrial structure, and implement cross-regional and cross-industry professional cooperation, which is, the implementation of economic circle development model so that the overall function of the park can be fully played.

2) Conducting structural reform of regional supply side: Adjusting the economic structure can help optimize the allocation of factors and enhance the quantity and quality of economic growth. The implementation of regional supply-side structural reform is conducive to solving the problems of uneven distribution of population and resources, unfair and uncoordinated. The supply-side reform in industrial parks will be conducive to rational and better allocation of resources and effective supply.

3) Conducting industrial undertaking and upgrading: Technological progress is an important factor to promote the transformation and development of industrial structure. We should strengthen technological innovation and upgrading, cultivate advantages and leading industries, strengthen industrial undertaking, rationally plan and give full play to comparative advantages, and always upgrade technology.

4) Taking advantage of the $B \& R$ Initiative: Yunnan is the "bridgehead" facing Southeast Asia and South Asia, which occupies the favorable location. We should strengthen economic and technological cooperation with neighboring countries and regions so as to penetrate the north and the south, and draw successful experiences from the eastern developed areas so as to achieve East-West integration.

5) Formulating negative list of pronvicial industrial development: The construction of industrial parks depends on the implementation and assistance of national policies. To formulate a negative list of industrial development can help eliminate and reduce unhealthy development of the industry. Rational planning and planned layout are needed for the government.

\section{REFERENCES}

[1] Weber, Alfred, Theory of the Location of Industries. University of Chicago Press, 1929.

[2] Granovetter, Mark, "Economic action and social structure: The problem of embeddedness." American journal of sociology 91, no. 3 (1985): 481510 .

[3] Scott, Allen J, "The Roepke lecture in economic geography the collective order of flexible production agglomerations: Lessons for local economic development policy and strategic choice." Economic Geography 68, no. 3 (1992): 219-233.

[4] Wang, Jizi, Innovation Spaces, Enterprises Clusters and Regional Development. Beijing University Press, 2001.

[5] Chen, Jianfeng, "A Research on the Knowledge-based Capability of Industrial Clusters", 2003, The Study of Finance and Economics, 2003,29(2), 62-69.
[6] Wu, Fuxiang, "An Analysis of the Restructuring of Industry Distribution in China from the Perspective of Welfare Economics," 2014, Social Socience in China, 2014(2), 96-115.

[7] Li, Zhaocheng, "Correlation Analysis between Industrial Structure and Urbanization in Qingdao", 2015, Modern Economics Information, 2015(3).

[8] Jia, Dehai, "Research on Industrial Layout of Yunnan Province Based on Cluster Theory", 2014, China Business \& Trade, 20(2014), 195-196.

[9] Liu, Ersi, "The development of Yunnan Industrial Park and the Construction of Financing System. Beijing, Economy\&Management publishing house ,2016 